NASA/TM-2005-213977

\title{
Mechanical Design of Carbon Ion Optics
}

Thomas Haag

Glenn Research Center, Cleveland, Ohio 
Since its founding, NASA has been dedicated to the advancement of aeronautics and space science. The NASA Scientific and Technical Information (STI) Program Office plays a key part in helping NASA maintain this important role.

The NASA STI Program Office is operated by Langley Research Center, the Lead Center for NASA's scientific and technical information. The NASA STI Program Office provides access to the NASA STI Database, the largest collection of aeronautical and space science STI in the world. The Program Office is also NASA's institutional mechanism for disseminating the results of its research and development activities. These results are published by NASA in the NASA STI Report Series, which includes the following report types:

- $\quad$ TECHNICAL PUBLICATION. Reports of completed research or a major significant phase of research that present the results of NASA programs and include extensive data or theoretical analysis. Includes compilations of significant scientific and technical data and information deemed to be of continuing reference value. NASA's counterpart of peerreviewed formal professional papers but has less stringent limitations on manuscript length and extent of graphic presentations.

- TECHNICAL MEMORANDUM. Scientific and technical findings that are preliminary or of specialized interest, e.g., quick release reports, working papers, and bibliographies that contain minimal annotation. Does not contain extensive analysis.

- CONTRACTOR REPORT. Scientific and technical findings by NASA-sponsored contractors and grantees.
- CONFERENCE PUBLICATION. Collected papers from scientific and technical conferences, symposia, seminars, or other meetings sponsored or cosponsored by NASA.

- SPECIAL PUBLICATION. Scientific, technical, or historical information from NASA programs, projects, and missions, often concerned with subjects having substantial public interest.

- TECHNICAL TRANSLATION. Englishlanguage translations of foreign scientific and technical material pertinent to NASA's mission.

Specialized services that complement the STI Program Office's diverse offerings include creating custom thesauri, building customized databases, organizing and publishing research results ... even providing videos.

For more information about the NASA STI Program Office, see the following:

- Access the NASA STI Program Home Page at http://www.sti.nasa.gov

- E-mail your question via the Internet to help@sti.nasa.gov

- Fax your question to the NASA Access Help Desk at 301-621-0134

- Telephone the NASA Access Help Desk at 301-621-0390

- Write to:

NASA Access Help Desk

NASA Center for AeroSpace Information 7121 Standard Drive

Hanover, MD 21076 
NASA/TM-2005-213977

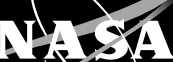

(8)

\section{Mechanical Design of Carbon Ion Optics}

Thomas Haag

Glenn Research Center, Cleveland, Ohio

Prepared for the

41st Joint Propulsion Conference and Exhibit

cosponsored by the AIAA, ASME, SAE, and ASEE

Tucson, Arizona, July 10-13, 2005

National Aeronautics and

Space Administration

Glenn Research Center 
Available from

NASA Center for Aerospace Information 7121 Standard Drive

Hanover, MD 21076
National Technical Information Service 5285 Port Royal Road Springfield, VA 22100

Available electronically at http://gltrs.grc.nasa.gov 


\title{
Mechanical Design of Carbon Ion Optics
}

\author{
Thomas Haag \\ National Aeronautics and Space Administration \\ Glenn Research Center \\ Cleveland, Ohio 44135
}

\begin{abstract}
Carbon Ion Optics are expected to provide much longer thruster life due to their resistance to sputter erosion. There are a number of different forms of carbon that have been used for fabricating ion thruster optics. The mechanical behavior of carbon is much different than that of most metals, and poses unique design challenges. In order to minimize mission risk, the behavior of carbon must be well understood, and components designed within material limitations. Thermal expansion of the thruster structure must be compatible with thermal expansion of the carbon ion optics. Specially designed interfaces may be needed so that grid gap and aperture alignment are not adversely affected by dissimilar material properties within the thruster. The assembled thruster must be robust and tolerant of launch vibration. The following paper lists some of the characteristics of various carbon materials. Several past ion optics designs are discussed, identifying strengths and weaknesses. Electrostatics and material science are not emphasized so much as the mechanical behavior and integration of grid electrodes into an ion thruster.
\end{abstract}

\section{Nomenclature}

$\begin{array}{ll}\text { E } & \text { elastic modulus } \\ \sigma_{\mathrm{f}} & \text { stress at failure } \\ \rho & \text { material density } \\ \mathrm{C}_{\mathrm{TE}} & \text { coefficient of thermal expansion } \\ \mu & \text { Poisson's ratio } \\ \mathrm{r} & \text { grid radius } \\ \mathrm{d} & \text { grid gap } \\ \mathrm{t} & \text { grid thickness } \\ \mathrm{p} & \text { electrostatic pressure } \\ \delta & \text { axial deflection }\end{array}$

\section{Introduction}

Electrostatic ion propulsion is being considered for a number of demanding space missions by NASA and other organizations. The high specific impulse provided by these thrusters is viewed as an enabling technology, without which some missions might be impossible. Some of the first efforts to fabricate carbon fiber ion optics were made by the Jet Propulsion Laboratory. These were relatively small ion optics assemblies, typically 10 to $15 \mathrm{~cm}$ in diameter (refs. 1 and 2). Circular and slit-type apertures were investigated, and implied major consequences on carbon fiber integrity (refs. 3 and 4). Success of the NASA Solar Electric Propulsion Technology and Readiness (NSTAR) program focused interest on $30 \mathrm{~cm}$ ion optics, and JPL fabricated carbon fiber ion optics intended as an alternative to the molybdenum grids that had been baselined (ref. 5). The more recent Carbon Based Ion Optics (CBIO) program directed significant resources toward large-diameter carbon optics, including both carbon fiber composites and pyrolytic graphite (refs. 6 and 7). NASA Glenn Research Center (GRC) successfully pursued pyrolytic graphite (PG) ion optics development under the Energetics Program, demonstrating good laboratory performance and structural integrity (refs. 8 and 9). Lessons learned in the CBIO program were used as a starting point for the higher power Nuclear Electric Xenon Ion System (NEXIS) thruster (ref. 10). In a similar way, NASA GRC designed and tested large PG ion optics designs under the High Power Electric Propulsion (HiPEP) program (ref. 11). There has also been significant international success with ion propulsion. The Artemis spacecraft, sponsored by the European Space Agency (ESA), was salvaged from a misplaced orbit through use of its RITA and EITA ion propulsion system (ref. 12). The Hayabusa mission is moving forward with the MUSES-C success (ref. 13). 
Sputter erosion of the grid electrodes will limit the functional life of an ion thruster. Dimensional changes to the screen and accelerator apertures will ultimately lead to the onset of electron backstreaming. The erosion rate of the grid electrodes depends on the voltage of thruster operation, and the material from which they are constructed. Since the 1950's, molybdenum has been commonly used to fabricate ion thruster grids, due to its low thermal strain, resistance to high temperature, and relatively low sputter erosion rate. Since the 1990's, carbon has received increased attention as a candidate material because it is significantly superior to molybdenum in all three of these areas. Carbon, however, is a non-metallic material, and introduces many manufacturing challenges. The thermal strain, elastic modulus, and ultimate strength of carbon can vary drastically, depending on its form. These properties are often inconsistent with commonly used metals within a thruster assembly. Special design considerations must be employed in order to accommodate carbon based materials. This paper will discuss some of the challenges that have surfaced in attempts to incorporate carbon materials into ion thrusters. The successes and failures of various projects will be discussed, spanning from the early 1990's through to the present.

\section{Forms of Carbon}

\section{A. Pyrolytic Graphite}

Structural carbon can take on different forms. Pyrolytic graphite is formed by chemically depositing carbon onto a precisely shaped mandrel. Hydrocarbon gas is admitted into a low pressure furnace, in excess of $1800^{\circ} \mathrm{C}$. The gas chemically cracks upon contact with the hot mandrel, leaving a stratified lattice of carbon that builds up over time. After cooling, the PG layer is dislodged from the mandrel and may undergo extensive post-machining. The material properties of PG are very anisotropic. Thermal conductivity and electrical conductivity exceed that for most metals in directions parallel to the deposition plane. Conversely, these qualities are quite poor in the direction normal to the deposition plane. PG is vulnerable to split or delaminate between planes, and care should be taken in designing parts to avoid this structural weakness. Its strength and elastic modulus are much higher parallel to the deposition plane, and produce excellent membrane-like shapes. Material density is typically about $2200 \mathrm{~kg} / \mathrm{m}^{3}$, which is near the theoretical maximum for graphite.

\section{B. Carbon Composites}

Carbon composites are fabricated with a preform of carbon fiber, consisting of filament tape or woven fabric. Multiple layers are often used in order to tailor strength properties within the part. Since internal forces within the part are carried primarily by the fibers, fiber density is kept to a maximum. Bonding between fibers is necessary in order to resist compressive and shear loads. Bonding is achieved by depositing additional carbon in between individual fibers, filling voids, and densifying the fiber matrix. Density is increased either by chemical vapor infiltration, or resin pyrolysis. The properties of carbon composites can be manipulated through careful selection of carbon fiber, and preform configuration. Care must be taken to avoid delamination between layers, and trapped regions of low density. Fibers are commercially available with different elastic modulus, tensile strength, and cost. Fiber properties can be modified by performing a post-densified heat treatment of the entire part. The combinations of fabrication techniques are endless. The maximum stiffness and strength of carbon composites are aligned with the fiber direction, and are significantly less in the cross-grain direction. Raw carbon fiber is available with a strength much higher than steel, however densified parts are seldom this strong because various ply directions are needed to distribute strength in all three axes. Thermal strain and conductivity are also aligned with fiber grain, with $\mathrm{C}_{\mathrm{TE}}$ values that vary from slightly negative, to moderately positive. Material density can vary widely depending on the fabrication process, but $1800 \mathrm{~kg} / \mathrm{m}^{3}$ is typical.

\section{Polycrystalline Graphite}

A relatively isotropic form of carbon can be produced by processing carbon powder in an isostatic press. Material properties vary depending on the powder grain size, and final density of the compacted block. Grain size is typically on the order of 10 microns. Graphite components are mechanically machined from blocks of material, with directional orientation being arbitrary. Material density varies from 1750 to $1920 \mathrm{~kg} / \mathrm{m}^{3}$, depending on the specified grade. The thermal strain rate varies slightly with density and grain size. Generally, $\mathrm{C}_{\mathrm{TE}}$ is uniform in all directions, and is comparable to that of molybdenum. Ultimate strength varies significantly with material grade. Flexural strength of $138 \mathrm{Mpa}(20 \mathrm{ksi})$ are available in small sizes, but elastic modulus is typically a fraction of that compared to PG. 


\section{Material Behavior}

\section{A. Sputter Erosion}

The sputter erosion rate for graphite is roughly an order of magnitude less than that of molybdenum. The exact rate is somewhat variable, depending on particle energy, incident angle of particle, surface finish, etc. Chargeexchange (pit and groove) erosion occurs on the downstream surface of an ion thruster accelerator grid. It is easily seen as a hexagonal honeycomb pattern among the apertures, and can ultimately lead to structural failure of the accelerator grid. Aperture barrel erosion is less visible, and occurs on the cylindrical wall of the accel apertures. As the diameter of the apertures increase, they will ultimately enlarge to the point where electron back-streaming cannot be prevented. For most space missions, aperture enlargement is viewed as the most likely failure scenario.

Recent data has indicated that carbon fiber composites and PG have roughly the same sputter erosion rate. The erosion rate for polycrystalline graphite is roughly 40 percent higher than carbon composites or PG (ref. 14). If material density is considered, PG is about 25 percent more dense than the others. There is concern that anisotropic forms of carbon will wear irregularly, leading to jagged surfaces, enhanced electric field, and more frequent intergrid arcs. While plausible, this issue has not been conclusively proven. There are numerous wear tests presently underway that could support or discount this concern.

\section{B. Thermal Strain}

Thermal strain affects the dimensional stability of ion optics. The $\mathrm{C}_{\mathrm{TE}}$ of most materials is a very small number, and results in linear expansion that is of little consequence. It is the differential expansion of various components that must considered. Choosing materials with the same $\mathrm{C}_{\mathrm{TE}}$ is not good enough, because temperature variations exist within an ion thruster that will cause differential expansion. The radial temperature distribution within most ion thruster grids is a clear example of this effect. If radial expansion within a flat disk exceeds hoop expansion, internal stress will develop. Radial compressive stress leads to buckling, and buckling dramatically amplifies geometric distortion. The flat disc with barely any height will become dish shaped. Instead of dimensions changing by only a tenth of a percent as predicted by linear theory, buckling amplifies this effect and height may increase by a factor of ten or more.

One way to reduce the chance of buckling is to select a material with a lower $\mathrm{C}_{\mathrm{TE}}$. The problem diminishes as $\mathrm{C}_{\mathrm{TE}}$ is reduced, and perfect stability is achieved when $\mathrm{C}_{\mathrm{TE}}$ is identically zero. There are no common metals with a $\mathrm{C}_{\mathrm{TE}}$ of zero, and invar-type materials are only effective over a narrow temperature span. Fortunately, there are carbon-based materials with very low $\mathrm{C}_{\mathrm{TE}}$, however they often meander with temperature between slightly negative and slightly positive. In the case of flat thin ion thruster grids, a slightly negative $\mathrm{C}_{\mathrm{TE}}$ works out well with a radial temperature distributions. Assuming the perimeter of the grid is clamped tightly to a rigid stiffening structure, the thin part of the grid will draw into tension. As with the skin of a drumhead, the grid surface will remain flat as long as the perimeter can tolerate the compressive hoop stress. This design can be implemented with certain types of carbon fiber composite or pyrolytic graphite, which have negative $\mathrm{C}_{\mathrm{TE}}$. While this may represent a thermal design solution, flat ion thruster grids remain vulnerable to structural issues of electrostatic deflection and launch vibration.

Another solution to the problem of buckling is to design-in spherical curvature throughout the radius of the grid. Almost all molybdenum optics are domed in order to permit controlled and predictable buckling as the thruster goes through each thermal cycle. Since temperature gradients are time dependent, some grid gap variation is inevitable with metallic optics. Fabrication complexity is significantly increased with domed optics in that curvature must be carefully matched, and aperture locations compensated for the diverging beam. Chemical etching of metallic grids is a very cost effective approach to form screen and accelerator apertures. Tens of thousands of apertures can be formed simultaneously, during an etching process that may take only an hour. Chemical etching can be performed on either flat or domed geometry, with no burs or strain-hardening of the metal. Unfortunately, carbon grids cannot be chemically etched with existing technology, and apertures must be drilled hole by hole. This is a time consuming and costly procedure, requiring high-precision 5-axis $\mathrm{CNC}$ machines.

Thermal strain can affect the structural integrity of an ion thruster. It is common practice in flight systems to maximize first mode resonant frequency by increasing structural stiffness. However, if a rigid optics frame is mated to a rigid ion thruster, there is risk of severe cyclical stress. Unless components are made from similar material, and operate at similar temperatures, it is advisable to design transition joints with some degree of strain isolation. What fits together at room temperature may see significant stress at operating temperature. It may take numerous thermal cycles for evidence to appear, but thermally induces structural fatigue can lead to system failure. Flexures need to be carefully designed to accommodate thermal strain of normal operation, yet survive launch vehicle dynamic loads. 


\section{Material Robustness}

There are a number of ways in which the ion optics assembly might be damaged. Areas-of-risk include manufacturing and assembly, launch vehicle vibration, and electric arcs. Under some circumstances, failure occurs at the onset of plastic deformation, where permanent distortion goes beyond geometric specifications. Under other circumstances, failure is not reached until the point of material rupture. The two words "Strength" and "Toughness" are sometimes confused as being interchangeable, but in reality they define different qualities. The following three scenarios distinguish different types of stress-induced effects.

1) A high strength material will tolerate high stress before failure. Silica glass has fairly high strength, but it also has a high elastic modulus. Stress levels increase at a very steep rate, and the material will shatter when impacted by a similar object. There is no ability to absorb impact energy via plastic deformation, and failure occurs as brittle fracture.

2) Silicone rubber has a low failure stress, and a very low elastic modulus. When impacted, the material elastically deforms, converting kinetic energy into strain energy. Large deformation may take place because the low modulus delays the buildup of stress, and fracture will not take place until ultimate stress is exceeded. Fairly high specific energies can be absorbed before material failure occurs. Under normal conditions, the strain energy will re-bound back to kinetic energy, with complete recovery to the original state. This type of response is typical of materials with high toughness.

3) Annealed copper has a low yield strength, and fairly high elastic modulus. Under impact, the high modulus quickly results in elevated stress levels within the material. Very little strain energy can be stored before plastic deformation begins. Because of its ductility, much cold-working may take place, where kinetic energy is irreversibly converted to heat. While the original geometry was lost very early, fracture is delayed by the cold-working process until strain-hardening reaches the ultimate stress limit. Ductile materials can absorb tremendous punishment before fracture occurs, and are often employed where human safety is a concerned. For ion optics, failure occurs when yield strength is exceeded, even though there is no fracture.

The maximum amount of strain energy that is storable in a material can be predicted by evaluating the strainenergy equation at the point of failure. If the material is linearly elastic,

$$
\frac{\text { Maximum Strain Energy }}{\text { (per unit volume) }} \frac{1}{2} \frac{\underset{\mathrm{f}}{\mathrm{E}}}{\mathrm{E}}
$$

where $\sigma_{\mathrm{f}}$ represents stress at failure, and $\mathrm{E}$ is the elastic modulus (ref. 15). The more a material can store strainenergy, the more it can resist damage. When a material exceeds its Maximum Strain Energy, it either plastically deforms, or fractures. Launch loads are an inertial effect in which the entire spacecraft is subjected to mechanical vibration. Dynamic stress is induced proportional to material density. As might be expected, the lightest materials will see the lowest dynamic stress. Conversely, a structure fabricated with high density material will experience higher dynamic stress. The Maximum Strain Energy equation can be recast into units of mass, such that:

$$
\frac{\text { Maximum Strain Energy }}{\text { (per unit mass) }} \frac{1}{2} \frac{2}{\mathrm{E}}
$$

where $\rho$ is material density. This number can be calculated for many different types of material in order to compare their relative resistance to dynamic loads. In table 1, strength is defined as either maximum yield strength or point of material fracture.

TABLE 1.-MAXIMUM STRAIN ENERGY OF VARIOUS MATERIALS.

\begin{tabular}{|l|l|c|c|c|}
\hline \multicolumn{1}{|c|}{ Material } & \multicolumn{1}{c|}{ Strength, Mpa } & Elastic Mod., Gpa & Density, $\mathrm{kg} / \mathrm{m}^{3}$ & Max Energy, J/kg \\
\hline \hline Stainless Steel & 207, yield & 193 & 8,030 & $\mathbf{1 3 . 8}$ \\
\hline Molybdenum & 655, yield & 324 & 10,220 & $\mathbf{6 4 . 8}$ \\
\hline Titanium & 483, yield & 103 & 4,850 & $\mathbf{2 3 3}$ \\
\hline C-C Comp. & 345, fracture & 206 & 1,830 & $\mathbf{1 5 8}$ \\
\hline Pyrolytic C & 89.6, fracture & 32.4 & 2,220 & $\mathbf{5 5 . 8}$ \\
\hline Polycrystalline C & 68.6, fracture & 12.7 & 1,900 & $\mathbf{9 7 . 5}$ \\
\hline
\end{tabular}


As seen in the table, high-strength materials are not necessarily the most damage resistant. Molybdenum has a very high yield strength, and is presently the most common metal used in ion optics. It has a relatively high density, resulting in higher stress under dynamic loads. The high elastic modulus results in good rigidity, but this also increases stress under shock loads. Pyrolytic graphite has an order of magnitude lower strength and stiffness, yet it has a comparable strain energy storage limit. The low density and elastic modulus of PG are an advantage, and permit significant storage of strain energy before stress induced failure occurs. Titanium shows very high strain energy storage, and has been considered as a possible replacement for molybdenum. Polycrystalline graphite has a very low elastic modulus, and can endure extreme deformation before failure occurs. Carbon-carbon composites show excellent potential for toughness, due to its high tensile strength. Anisotropic materials must be considered with caution because subtle vulnerabilities may exist. The strain energies tabulated above represent macroscopic generalizations, and may be overly optimistic at small length scales. Flakes or chips are sometimes dislodged from larger components, posing an arc hazard. Both pyrolytic graphite and carbon composites are prone to inter-laminar separation, requiring careful design consideration.

\section{Electrostatic Attraction}

There is a mutual attraction force between the screen and accelerator grids due to applied voltage across the gap. Even the open area of the screen grid is bridged over by fringe effects, and contributes to the pull of the electric field. A first-order estimate of the electrostatic pressure $\mathrm{p}$ on the grids can be approximated by (ref. 16)

$$
\mathrm{p} \frac{\mathrm{V}^{2}}{2 \mathrm{~d}^{2}}
$$

where $\varepsilon$ is permittivity of free space $\left(8.842 \times 10^{-12} \mathrm{C}^{2} \mathrm{~N}^{-1} \mathrm{~m}^{-2}\right)$. For a flat circular grid, this force deflects the surface in a way similar to hydrostatic pressure, and can be estimated as (ref. 17)

$$
\frac{3}{16} \operatorname{pr}^{4}(1 \quad)(5 \quad) /\left(\mathrm{Et}^{3}\right)
$$

Deflection $\delta$ must be calculated for both the screen and accelerator grid in order to determine constriction of the grid gap. Material macro-properties may be chosen to account for high open-area, because the equation assumes a uniform disk, of radius $r$, and thickness $t$. If the change in grid gap is significant, flat grids may not be a workable design. As the gap is drawn together, the attraction force increases. Ultimately, a run-away situation is reached where the grids come into contact and temporarily short. Either the grids must be strengthened, or the electric field must be reduced. A shallow spherical dome has tremendous stiffness relative to a flat disk. Manufacturing a dome, however, is factors more complex.

\section{Design of Carbon-Metallic Interface}

The screen grid and accelerator grid of an ion thruster can be made of carbon in order to take advantage of the sputter resistant properties of this material. The thermal strain rate of carbon is often very low, resulting in good geometry stability of the aperture alignment. The majority of the spacecraft, however, is often metallic, with considerably higher thermal strain rate. Tubing, wire, magnetic components, and general structure are often made of

aluminum, stainless steel, or titanium. Eventually, there must be an interface between the carbon ion optics and the metallic assemblies, and this interface needs to accommodate differing strain rates.

\section{A. Ground Based Applications}

A number of industrial ion sources simply support the carbon optics components with oversized clearance holes. The accelerator grid is loosely held, with as much as a millimeter of free radial movement within the grid plane. The screen is tightly coupled to the accelerator grid via ceramic insulators. Several insulators are positioned around the perimeter, to establish grid gap and aperture alignment. Since they are of the same material, differential expansion is not an issue. The pair are permitted to float relative to the ground structure, as the thruster goes through each thermal cycle. For industrial applications, this is a very simple and functional design. A loose optics assembly, however, might be expected to rattle quite violently under launch vehicle vibration, making this unacceptable for a flight design. 


\section{B. Early $30 \mathrm{~cm}$ Carbon-Carbon}

In the mid 1990s, JPL fabricated a C-C composite ion optics assembly under contract with NASA (ref. 5). The design was intended to be compatible with the NSTAR $30 \mathrm{~cm}$ thruster, which was baselined with molybdenum optics. Shallow domed screen and accelerator grids were mounted onto a $\mathrm{C}-\mathrm{C}$ composite mounting ring via ceramic insulators. The optics assembly was completely non-metallic, except for fasteners (see fig. 1). It was self-contained, permitting grid gap and aperture alignment prior to installation on the thruster. The screen grid and accelerator grid were made from six plies of prepreg fiber ribbon. The layers were symmetrically stacked, with fiber direction staggered at $60^{\circ}$ intervals. Blank panels were carbonized, graphitized, and Chemical Vapor Infiltration (CVD) densified over a domed mandrel. Apertures were laser machined into the blank panels to complete the screen and accelerator grids. A mounting ring was made from carbon fiber fabric using a design very similar to the titanium mounting ring in the NSTAR thruster. The screen grid attached directly to the mounting ring via machine screws. The accelerator grid was suspended away from the screen on ceramic insulators identical to those used by NSTAR. Precise grid gap was to be adjusted by placing shims between the accelerator grid and the insulator mounting face. Unfortunately, the spherical curvature of the two grids did not match, resulting in severe gap variation along the radius. The carbon optics assembly was rigidly mated to the metallic NSTAR thruster through 6 ceramic insulators. There was no specific design feature intended to accommodate the different strain rates between the carbon optics and the thruster. The severe non-uniform grid gap prevented the optics from being operated at full power, so the carbon-metallic interface was never tested under design conditions.

\section{Eight cm Pyrolytic Graphite}

An $8 \mathrm{~cm}$ pyrolytic graphite optics assembly was tested at NASA GRC in 2002 (ref. 8). The flat grids had aperture geometry similar to that of NSTAR, and were aligned on a C-C composite mounting ring (see fig. 2). The self contained optics assembly was mated to the metallic ion thruster via 4 ceramic insulators, similar to the JPL approach. The insulators were long relative to the grid diameter, which may have eased the strain mismatch. The thruster discharge chamber was oversized relative to the optics assembly, and represented a laboratory configuration. It ran well, with no consequences from the simple interface.

\section{Thirty cm Pyrolytic Graphite, GRC}

Success of the flat $8 \mathrm{~cm}$ PG ion optics was quickly followed by fabrication of domed $30 \mathrm{~cm}$ PG optics (ref. 9). The screen grid, accelerator grid, screen stiffener, and accelerator stiffener were designed to be similar to molybdenum components used on NSTAR. The grids were attached to the stiffeners using small machine screws, and then installed on a titanium mounting ring of NSTAR design. Radial strain accommodation for the screen grid was achieved by flexures integral with the original NSTAR mounting ring. Radial strain accommodations for the accelerator grid was absent from the original NSTAR design, and needed to be addressed. New mounting posts were fabricated for the accelerator grid which incorporated face-to-face leaf spring flexures. At room temperature, the facing leaf springs were fully compressed, and nearly bottomed out. As the temperature of the titanium mounting ring increased, it expanded radially relative to the accelerator grid and began to draw the leaf springs apart. The flexure design was axially rigid, but very compliant in the radial direction. The flexures were also rigid in the tangential direction, allowing for precise alignment between the screen and accelerator apertures. The new flexures were compact enough to be installed without any modification to the NSTAR insulators or mounting ring. Thruster performance with PG ion optics was similar to that of NSTAR, and easily covered the entire operating envelope. There was some grid gap variation due to non-spherical aberration in the screen grid. Some performance differences might have been due to cylindrically machined apertures instead of chemically etched apertures. The cusp normally present from the etch process would behave as an exceptionally thin screen grid, improving screen grid transparency. The mechanical drilling of the carbon screen left a more blunt aperture edge, reducing transparency.

Upon completion of performance measurements, the $30 \mathrm{~cm}$ pyrolytic ion optics began structural dynamic testing. Modal testing revealed a first mode resonance of $504 \mathrm{~Hz}$ with the screen grid, and $664 \mathrm{~Hz}$ with the accelerator grid (see fig. 3). The ion optics were then installed on NSTAR EMT1c for vibration testing. Random vibration level was gradually stepped up, and eventually reached DS-1 acceptance level for 60 seconds. Grid-to-grid contact was initially detected at $2 \mathrm{Grms}$, and was very intense at $9.3 \mathrm{Grms}$. The ion optics assembly showed no sign of damage after the test, although a small amount of fine carbon dust was collected under the grids.

\section{E. CBIO Program}

The CBIO program consisted of parallel efforts with the intention of developing large scale carbon ion optics. A carbon-carbon composite approach was pursued by the Jet Propulsion Laboratory, and a pyrolytic graphite approach was pursued by Boeing EDD (refs. 6 and 7). Both approaches were sized to a modified NSTAR geometry, and 
intended to be mountable as a substitute for the original molybdenum optics.

The pyrolytic graphite approach used a spherically domed accelerator grid and modified dome screen grid. The original NSTAR titanium mounting ring was essentially unchanged from NSTAR, and began as the basis for the new design. The mounting ring was naturally compatible with the rest of the NSTAR thruster, which was essentially spin formed titanium. Ceramic insulators were attached to the mounting ring, which electrically isolated the accelerator grid from the screen grid, and the screen grid from the anode. Both grids were mounted on titanium stiffeners and held in place with titanium clamping rings. Each pyrolytic graphite grid was loosely sandwiched between the stiffener and the clamp, but allowed to slide radially as materials expanded at different rates. Graphite foil was inserted to help dampen and lubricate radial movement. Short radial slots in the grid flange were to follow pins in the stiffener to prevent tangential motion and allow uniform radial expansion. Unfortunately, there were a number of problems with carbon grid fabrication, and particularly so with the screen grid. The first set of carbon grids experienced stress relief distortion upon machining, resulting in mismatch between the spherical curvature. The flange surrounding both carbon grids was not flat and became canted by a few degrees. The screen grid developed cracks along rows of aperture holes that spanned inches in length. Many of these flaws were corrected by implementing an extra stress relief process to the furnace cycle, and through staged machining. Once successfully assembled, the pyrolytic graphite ion optics was installed on NSTAR EMT1c and vibration tested to DS-1 levels. No grid-to-grid contact was detected with the CBIO PG design, no physical damage was detected, and aperture alignment was unchanged. Performance measurements of the PG ion optics were conducted at Boeing EDD. Very high accelerator currents were measured, suggesting that there may have been poor aperture alignment, or distorted gap. Visual observation of the thruster under operation revealed a red-orange glow on the accelerator grid, leaving little doubt that direct accelerator impingement was occurring. It is conceivable that jammed movement in the stiffener/grid interface could have adversely affected grid alignment or gap.

The carbon-carbon composite ion optics developed under CBIO followed a much different development path. A fresh design was started, which was made almost completely of carbon fiber. Both screen and accelerator grids were intended to have uniform spherical curvature, with heavy stiffening rings around each grid perimeter. Both grids consisted of layered uni-directional fiber tape, with each layer clocked $60^{\circ}$ relative to the next. The layups were carbonized and densified over a spherical mandrel. Apertures were laser machined into both grids, and a final CVD deposition was coated over all surfaces. The curvature of the mandrels was adjusted to account for heat treatment and laser machining effects. Adjustments were empirical, and solved the grid gap variation problem experience in the early $30 \mathrm{~cm}$ work. A double-walled cylinder mounting ring was made from carbon fiber, and provided extreme rigidity to the optics assembly (see fig. 4). The carbon fiber screen grid was bonded directly to the mounting ring. Ceramic insulators were recessed within the walls of the mounting ring, on which the accelerator grid was installed. A flat carbon fiber stiffener was bonded around the perimeter of the accelerator grid, and shimmed to the correct grid gap via the insulators. Since the entire optics structure was made from carbon fiber, thermal strain was nearly zero for all components. While the thruster mounting ring was electrically isolated from the anode with rigid ceramic insulators, strain isolation at this transition was not addressed. The extreme stiffness of the mounting ring likely dominated the interface. Vibration tests were conducted at various levels of assembly, beginning with individual grids. The ion optics were then tested as an assembly, and later installed on EMT1c. Ultimately, the carbon-carbon composite ion optics were tested on the thruster, meeting the $9.1 \mathrm{Grms}$ acceptance level. There was no observed contact between grids, and no damage was detected following the test. Ion thruster performance was mapped out over operating conditions defined at the start of the program. Thruster performance was good, and only fell short at the maximum beam current operating point. Initial rate of recycle was much lower than expected. The thruster was wear tested for 1028 hours without serious incident; however this fell short of the intended 2000 hour test. The ion optics were in fairly good condition following this test. There were some minor delaminations and broken webs, but some of this was traceable to initial fabrication.

\section{F. NEXIS}

The ion optics used in the $20 \mathrm{~kW}$ NEXIS DM is essentially a carbon fiber assembly scaled up from CBIO (ref. 10). A double walled cylinder formed the thruster mounting ring, and the screen grid was bonded directly to the ring (see fig. 5). Insulators were recessed into the hollow volume of the ring, and isolated the accelerator from the screen. Shims were placed between the insulator and accelerator grid in order to adjust grid gap. Except for fasteners, the entire NEXIS optics assembly was made of carbon fiber, which reduced thermal strain to near zero. Since the thruster chamber was a metallic assembly, strain isolation was necessary across this interface. An early design consisted of an array of 18 " $\mathrm{C}$ " flexures distributed around the interface from the carbon mounting ring to the thruster chamber. Elevated stress levels were predicted, so the design was replaced with an array of 9 bipod flexures. Each flexure pair spanned from the back of the carbon mounting ring, to a metallic bulkhead surrounding the 
thruster chamber. The bipods were flexible in the radial direction, but self-bracing for stiffness in the axial and tangential directions. Electrical isolation between the bipod and the thruster completed the design. The NEXIS thruster performed well, with few structural issues. The thruster began what is planned to be a 2000 hour wear test to determine the effect of sputter erosion on optics geometry, and thruster performance.

\section{G. HiPEP}

The $20 \mathrm{~kW}$ HiPEP Gen $1 \mathrm{~b}$ thruster had flat, rectangular, PG grids (ref. 11). They were the largest single-piece PG components that could be commercially manufactured. The screen grid and accelerator grid were independently mounted off a downstream frame, which was at ground potential. PG stiffeners were mounted directly to the perimeter of both grids, and each set of stiffeners was supported by an array of 22 flexures. The flexures accommodated thermal expansion of the discharge chamber and optics mounting frame. All flexures were rigid in the axial direction. However, they were all flexible radially outward from a single point at the centroid of the rectangle. The fixed end of the flexures were anchored to individual ceramic insulators. The insulators were mounted to a forward frame structure, in-place of what is commonly referred to as the front mask. This laboratory design allowed for relatively easy grid gap adjustment and aperture alignment. Although Gen $1 \mathrm{~b}$ operated very well, the downstream oriented optics frame was an issue of concern. It was felt that beamlet divergence in excess of $45^{\circ}$ might become a life limiting impingement issue, so an extensive redesign was pursued.

A second generation HiPEP thruster used the same PG grid electrodes, but with a completely different mounting arrangement. The screen and accelerator grids were independently mounted off an upstream frame in order to provide a much greater plume clearance angle. Grid extensions were necessary in order to straddle the discharge chamber. One hundred stainless steel extension fingers surrounded the perimeter of each grid (see fig. 6). The fingers were designed to pivot at both ends, allowing differential expansion between the PG grids and metallic grid stiffeners. Four centerline fingers were rigid, and keyed to prevent drifting of screen to accelerator alignment. The stainless steel stiffeners were supported by a series of tandem flexures, which allowed movement orthogonal to that of the extension fingers. The extension finger and flexure arrangement was very complex, but was intended to provide similar behavior if a large enough sheet of PG were available. The design worked well as a laboratory thruster, but larger sheets of PG or an integral carbon frame extender would be necessary for a vibration tolerant flight design. The ion optics assembly was mated to the thruster chamber through a series of tie rods, connecting the two frames. Thruster performance matched predictions very well (ref. 18). Grid to grid arcs were relatively frequent at first, but subsided to about one per hour after about 100 hours of operation. The thruster has recently completed 2100 hours of wear testing, but condition of the electrodes is not known as of this writing. Structural dynamic tests were performed at Aerojet Corporation using identical pyrolytic graphite grids (ref. 19). Aluminum grid extenders were installed around the perimeter of each grid to simulate how a larger flight representative thruster might behave. The optics set was vibration tested at DS-1 levels for 60 seconds. Heavy grid-to-grid contact occurred, but no significant structural damage was observed. A $2.0 \mathrm{~g}$ extended sine sweep was also preformed on the grid set, with similar results.

\section{Conclusion}

Carbon Ion Optics are expected to provide much longer thruster life due to their resistance to sputter erosion. Ion thruster optics can be fabricated from carbon fiber composites, pyrolytic graphite, or polycrystalline graphite. All three of these carbon materials can store significant amounts of strain energy, and should be resistant to impact loads. The mechanical behavior of carbon is much different than that of most metals, and poses unique design challenges. In order to minimize mission risk, the behavior of carbon must be well understood, and components designed within material limitations. Thermal expansion of the thruster structure must be compatible with thermal expansion of the carbon ion optics. Specially designed interfaces may be needed so that grid gap and aperture alignment are not adversely affected by dissimilar materials within the thruster. The assembled thruster must be robust, and tolerant of launch vibration. Carbon ion optics hardware has improved significantly over the past 10 years. 


\section{References}

1. Garner, C.E. and Brophy, J.R., "Fabrication and Testing of Carbon-Carbon Grids for Ion Optics," AIAA Paper 92-3149, 28th Joint Propulsion Conference, Nashville, TN, July 6-8, 1992.

2. Mueller, J., et al., "Performance Characterization of 15-cm Carbon-Carbon Composite grids," AIAA Paper 94-3118, 30th Joint Propulsion Conference, Indianapolis, IN, June 27-29, 1994.

3. Brophy, J.R., et al., "Carbon-Carbon Ion Engine grids with Non-Circular Hole Apertures," AIAA Paper 95-2662, 31st Joint Propulsion Conference, San Diego, CA, July 10-12, 1995.

4. Meserole, J.S., and Rorabach, M.E., "Fabrication and Testing of 15-cm Carbon-Carbon grids with Slit Apertures," AIAA Paper 95-2661, 31st Joint Propulsion Conference, San Diego, CA, July 10-12, 1995.

5. Mueller, Juergan, et al., "Design, Fabrication and Testing of 30-cm Dia. Dished Carbon-Carbon Ion Engine Grids," AIAA Paper 96-3204, July 1996.

6. De Pano, M.F., et al., "Fabrication and Vibration Results of 30-cm Pyrolytic Graphite Ion Optics," AIAA Paper 2004-3615, 40th Joint Propulsion Conference, Fort Lauderdale, FL, July 11-14, 2004.

7. Snyder, J.S., et al., "Performance Characterization and Vibration Testing of 30-cm Carbon-Carbon Ion Optics," AIAA Paper 2004-3959, 40th Joint Propulsion Conference, Fort Lauderdale, FL, July 11-14, 2004.

8. Haag, T.W., and Soulas, G., "Performance of 8-cm Pyrolytic Graphite Ion Thruster Optics," AIAA Paper 2002-4335, 38th Joint Propulsion Conference, Indianapolis, IN, 2002.

9. Haag, T.W., and Soulas, G., "Performance and Vibration of 30-cm Pyrolytic Ion Thruster Optics," AIAA Paper 2003-4557, 39th Joint Propulsion Conference, Huntsville, AL, 2003.

10. Monheiser, J., et al., "Conceptual Design of the Nuclear Electric Xenon Ion System (NEXIS) Engine," AIAA Paper 2004-3614, 40th Joint Propulsion Conference, Fort Lauderdale, FL, July 11-14, 2004.

11. Williams, G., et al., "Performance Characterization of HiPEP Ion Thruster Optics," AIAA Paper 2004-3627, 40th Joint Propulsion Conference, Fort Lauderdale, FL, July 11-14, 2004.

12. Killinger, R., et al., "Orbit Raising with Ion Propulsion on ESA's ARTEMIS Satellite," AIAA Paper 20023672, 38th Joint Propulsion Conference, Indianapolis, IN, 2002.

13. Hayakawa, Y., et al., "Endurance Test of $\mathrm{C} / \mathrm{C}$ grids for 14-cm Xenon Ion Thrusters," AIAA Paper 20023958, 38th Joint Propulsion Conference, Indianapolis, IN, 2002.

14. Williams, John, "Differential Sputtering Behavior of Pyrolytic Carbon and Carbon-Carbon Composites," September 7, 2004.

15. Rivello, R.M., Theory and Analysis of Flight Structures, McGraw-Hill, 1969, page 113.

16. Lorrain, P., and Corson, D., Electromagnetic Fields and Waves, W.H. Freeman and Company, 1988, page 111.

17. Lindeburg, M., Mechanical Engineering Reference Manual, Professional Publications Inc., 1994, chapter 14.

18. Williams, G., et al., "Performance Characterization of a $25 \mathrm{~kW}$, High-Specific Impulse Ion Thruster," AIAA Paper 2005-4248, 41st Joint Propulsion Conference, Tucson, AZ, 2005.

19. Polaha, J., et al., "Random and Sine-Spectrum Vibration Testing of Pyrolytic graphite Ion Optics," AIAA Paper 2005-4395, 41st Joint Propulsion Conference, Tucson, AZ, 2005. 


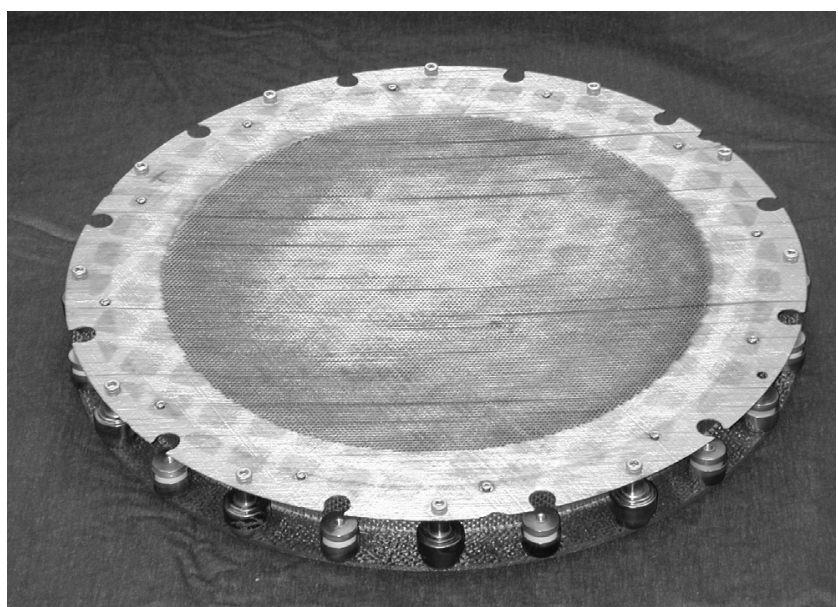

Figure 1.-Early $30 \mathrm{~cm}$ carbon-carbon ion optics assembly.

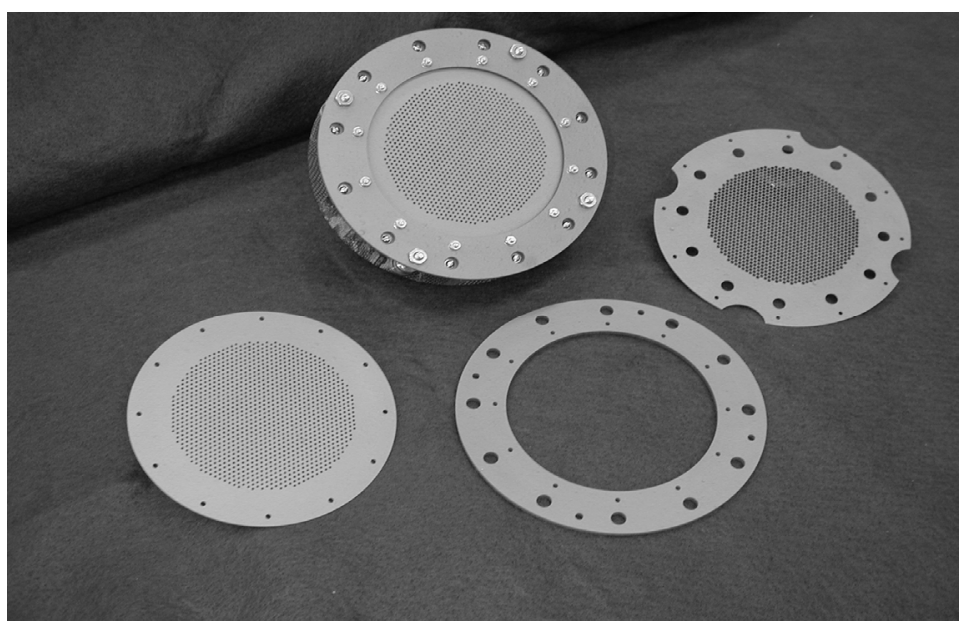

Figure 2.-Eight centimeter pyrolytic graphite ion optics assembly.

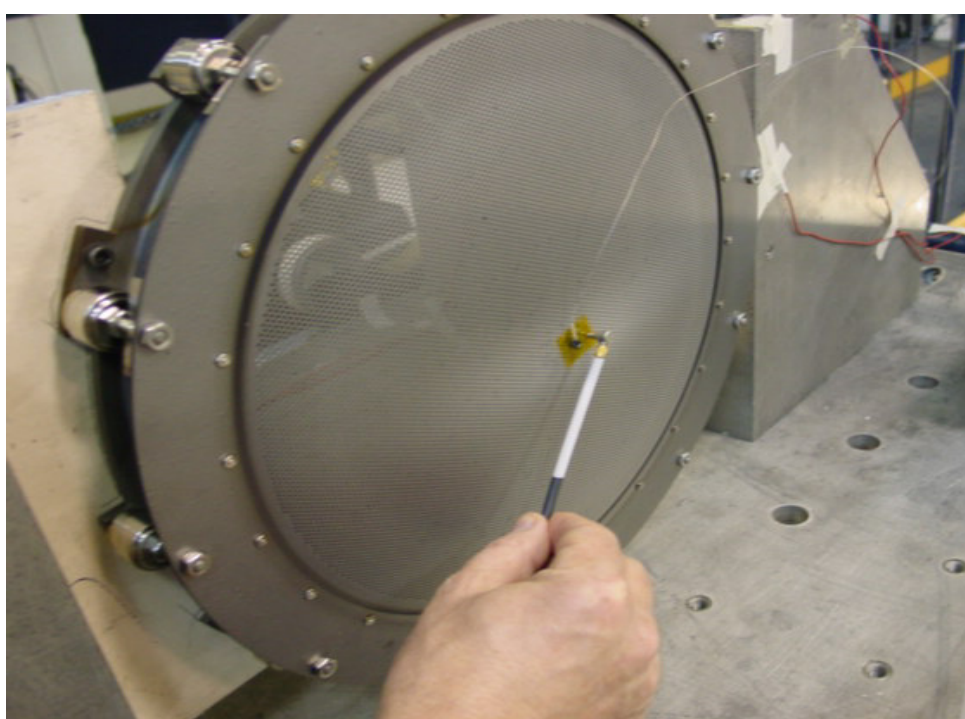

Figure 3.-Thirty centimeter pyrolytic graphite ion optics assembly. 


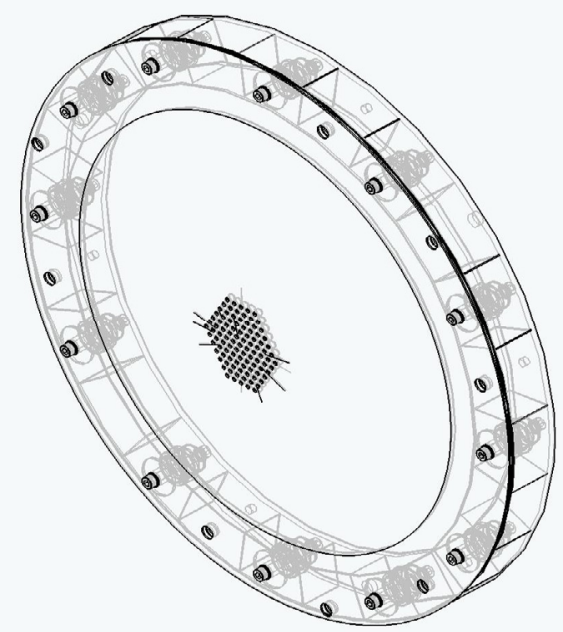

Figure 4.- CBIO carbon-carbon ion optics assembly.

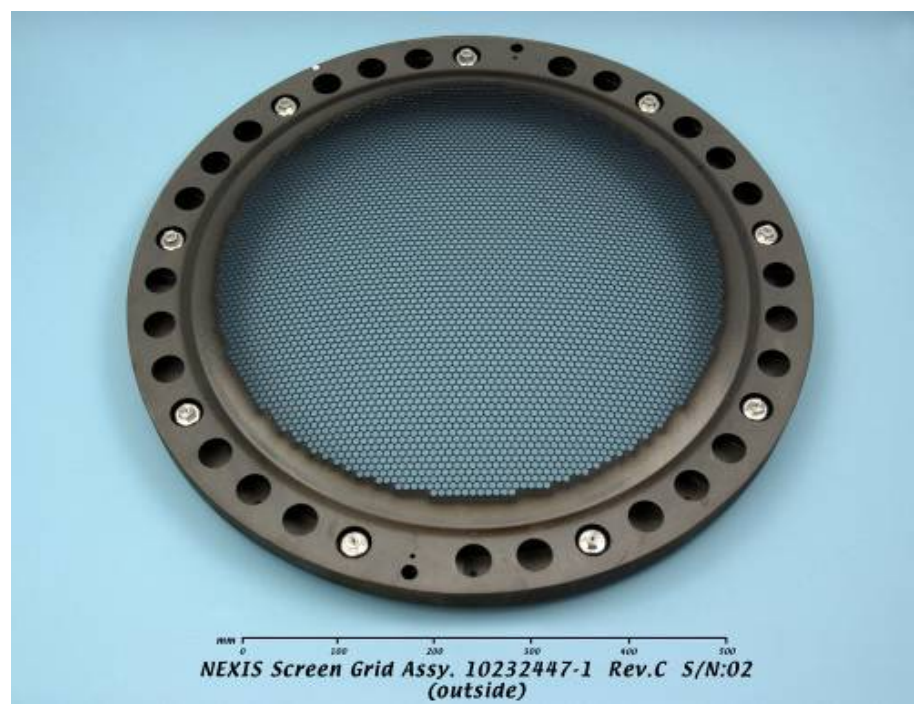

Figure 5.- NEXIS carbon-carbon screen grid and mounting ring.

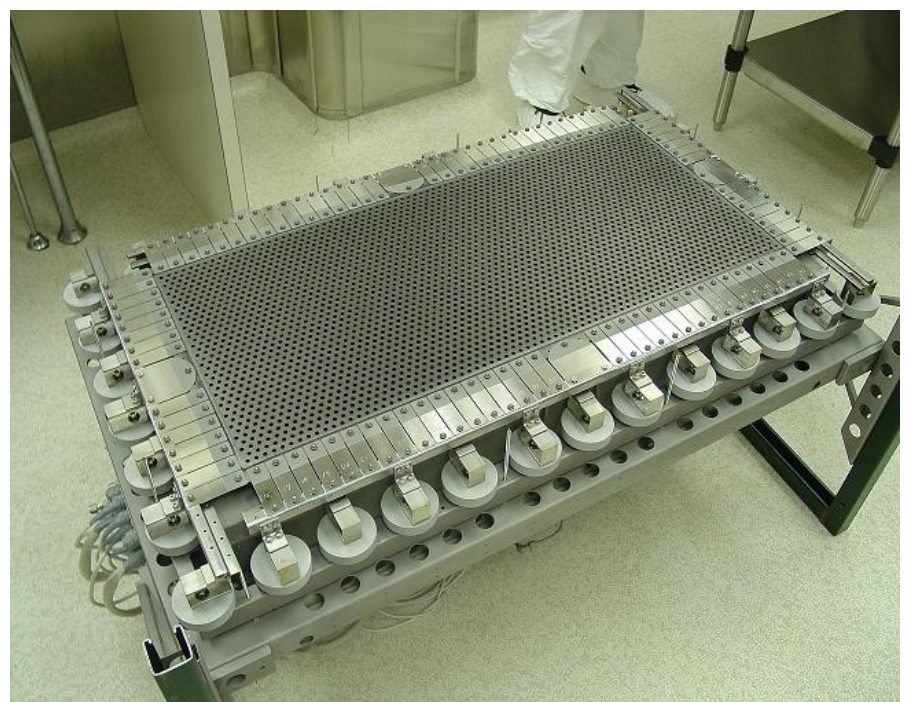

Figure 6.-HiPEP Gen2 laboratory PG ion optics assembly. 


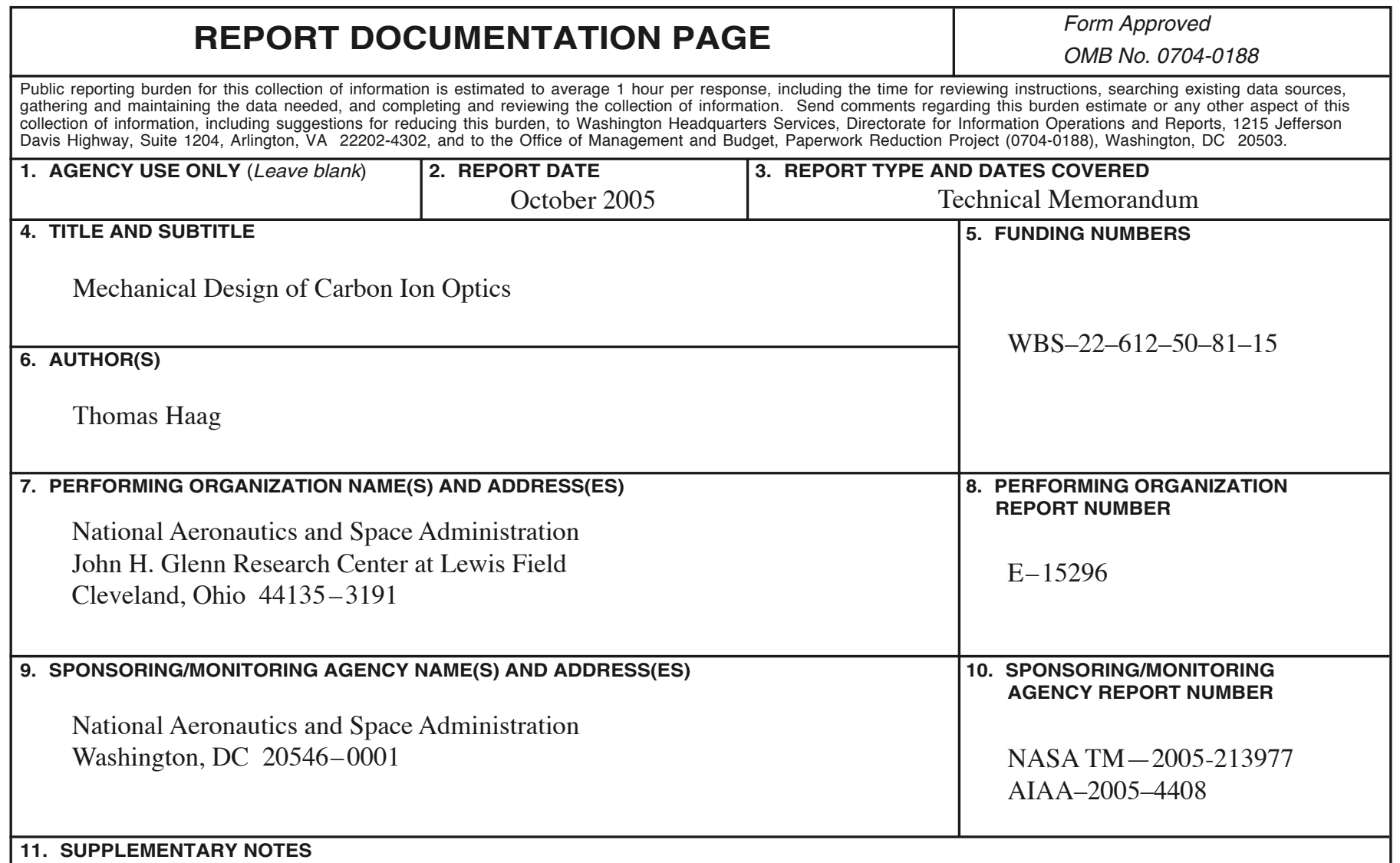

Prepared for the 41st Joint Propulsion Conference and Exhibit cosponsored by AIAA, ASME, SAE, and ASEE, Tucson, Arizona, July 10-13, 2005. Responsible person, Thomas Haag, organization code RPP, 216-977-7423.

\begin{tabular}{|l|l|l|l|l}
\hline 12a. DISTRIBUTION/AVAILABILITY STATEMENT & DISTRIBUTION CODE
\end{tabular}

Unclassified - Unlimited

Subject Categories: 20 and 24

Available electronically at http://gltrs.grc.nasa.gov

This publication is available from the NASA Center for AeroSpace Information, 301-621-0390.

13. ABSTRACT (Maximum 200 words)

Carbon Ion Optics are expected to provide much longer thruster life due to their resistance to sputter erosion. There are a number of different forms of carbon that have been used for fabricating ion thruster optics. The mechanical behavior of carbon is much different than that of most metals, and poses unique design challenges. In order to minimize mission risk, the behavior of carbon must be well understood, and components designed within material limitations. Thermal expansion of the thruster structure must be compatible with thermal expansion of the carbon ion optics. Specially designed interfaces may be needed so that grid gap and aperture alignment are not adversely affected by dissimilar material properties within the thruster. The assembled thruster must be robust and tolerant of launch vibration. The following paper lists some of the characteristics of various carbon materials. Several past ion optics designs are discussed, identifying strengths and weaknesses. Electrostatics and material science are not emphasized so much as the mechanical behavior and integration of grid electrodes into an ion thruster.

14. SUBJECT TERMS

15. NUMBER OF PAGES

Space propulsion; Ion thruster; Electric propulsion 17

\begin{tabular}{|c|c|c|}
\hline $\begin{array}{c}\text { 17. SECURITY CLASSIFICATION } \\
\text { OF REPORT } \\
\text { Unclassified }\end{array}$ & $\begin{array}{c}\text { 18. SECURITY CLASSIFICATION } \\
\text { OF THIS PAGE } \\
\text { Unclassified }\end{array}$ & $\begin{array}{c}\text { 19. SECURITY CLASSIFICATION } \\
\text { OF ABSTRACT } \\
\text { Unclassified }\end{array}$ \\
\hline
\end{tabular}

NSN 7540-01-280-5500

Standard Form 298 (Rev. 2-89)

Prescribed by ANSI Std. Z39-18 298-102 

